\title{
Pathophysiology of Memory Inception and Retrogression and Clock Dependent Divergence in Cognizance
}

\author{
Md. Arifur Rahman Chowdhury, ${ }^{1,2}$ Md Mazedul Haq ${ }^{3}$, Narayan Kumar ${ }^{4}$, and Chandresh Sharma ${ }^{5}$ \\ 'Department of Pharmacy, State University of Bangladesh, Dhaka, Bangladesh \\ ${ }^{2}$ Department of Pharmacy, Southeast University, Banani, Dhaka, Bangladesh \\ ${ }^{3}$ Department of Biochemistry, National University, Gazipur, Bangladesh \\ ${ }^{4}$ NIIT University, Neemrana, Rajasthan, India \\ ${ }^{5}$ Multidisciplinary Clinical Translational Research, Translational Health Science and Technology Institute, Faridabad, Haryana, India
}

\begin{abstract}
Our body (mammals) has a direct connection with the earth's axial cycle, which is similar to the universal concept of phenotype, representing the result of genotype-environment interactions in all living organisms. Collectively, 24-hour phases of day and night are termed circadian rhythms. It corresponds with body clocks to adapt and optimize physiology according to the changes in the surroundings. Contemporary studies in vertebrate and invertebrate models have revealed circadian rhythms (time and light) affect neurophysiology and cognitive performance. However, a clear understanding of the underlying mechanism of the genetic, molecular, and complex process of memory formation is yet to be confirmed. In this review, we are focusing on the effects of the biological clock on memory inception and retrogression along with clock dependent cognizance.
\end{abstract}

Key Words: Circadian rhythms; Melatonin; Biological clock; Memory formation; Neurophysiology

Received: February 24, 2021 Revised: April 9, 2021 Accepted: April 19, 2021

Corresponding author: Chandresh Sharma, MSc, PhD, Multidisciplinary Clinical Translational Research, Translational Health Science and Technology Institute, NCR Biotech Science Cluster, 3rd Milestone, Faridabad-Gurugram Expressway, PO box \#04, Faridabad-121001 (Haryana), India.

Tel: 91-1292876379, Fax: 91-1292876402, E-mail: chandresh@thsti.res.in

(a) This is an Open Access article distributed under the terms of the Creative Commons Attribution Non-Commercial License (https://creativecommons.org/licenses/by$\mathrm{nc} / 4.0)$ which permits unrestricted non-commercial use, distribution, and reproduction in any medium, provided the original work is properly cited.

\section{INTRODUCTION}

The body clock regulation is quite complex to describe in a simple manner. For instance, when the body is symbolized as a machine, that operates all of its staff in a synchronized way, continuously affected by the frame of time and light propensity. As a result, environmental factors such as light and darkness, as well as the body clock (endogenous circadian rhythms) work in unison to improve hemostasis, including the cell cycle, body temperature, feeding, metabolism, and, perhaps most importantly, the sleep-wake cycle as well as memory formation and consolidation [1].

Physiological, biological, and behavioural processes in mammals are regulated by circadian rhythms. The endogenous biological clock is located in the suprachiasmatic nuclei (SCN), a small group of hypothalamic nerves, recognized as the master circadian pacemaker. It is positioned unswervingly above the op- tic chiasm $[2,3]$ synchronically and functionally regulates the circadian rhythms of mammals throughout the 24-hour oscillations and secures every essential physiological process $[4,5]$.

In the 1970s, the role of SCN to drive the circadian rhythm was coined for the first time, but the molecular basis of the effects on physiology and behaviour in mammals finally became clear in the late 1990s. The SCN electrical activity and divergent state activity depend on circadian variations (day-night oscillation) [6]. Any unfavourable condition in SCN abolishes the regulatory mechanism. On the contrary, upon restoration of SCN, the circadian rhythms move smoothly [7-11].

\section{REGULATORY MECHANISM OF SCN AND CLOCK GENE ACTIVATION}

The photoreceptors of the retina are sensitive to light intensity. Expressed photopigment melanopsin is detected by the rods and 
cones as well as photosensitive retinal ganglion cells. Upon receiving the processed-light/signals to the $\mathrm{SCN}$ via the retinohypothalamic tract, finally the intracellular molecular clock mechanism is activated through enhancement of positive (BMAL1 and CLOCK as activators) and negative [period (PER) and cryptochrome (CRY) proteins] elements $[11,12]$.

\section{Interaction between clock function and memory formation}

As the body maintains clock dependent gene expression/activation/suppression, particular genes and genetic interactions are responsible for memory and memory formation. However, the original roles of local brain circadian clocks in memory formation remain unclear.

The molecular mechanisms facilitating circadian rhythm generation in the SCN are well studied: BMAL1 and CLOCK form a heterodimer and trigger the transcription of their target genes, including the period (PER1, PER2) and the cryptochrome (CRY1, CRY2) [13-18]. PERs and CRYs both genes inhibit the BMAL1/ CLOCK-mediated transcription in a negative feedback loop, thereby generating circadian transcriptional rhythms $[13,14]$.

\section{Are clock genes being memory genes?}

Drosophila melanogaster, a model organism, showed time-dependent eclosion rhythm depending on their strain. It proposes a genetic basis for the circadian regulation of this process, prompting a forward mutagenesis screen that identified the first clock gene, period (PER) [19-21]. Interestingly, these mutations cause correlative changes in the circadian locomotor activity rhythm in adult flies.

It is important to resolve the confusion about the relationship between the clock gene and memory formation. This relationship is strongly confirmed by the phenomenon where the clock gene independently forms memory and has roles in eclosion or the generation of circadian rhythms [22-26].

\section{CIRCADIAN RHYTHMS AND MEMORY}

The impact of time-of-day effects and circadian rhythms on cognitive performance and memory formation in humans [2729] have been studied for decades, and there has been a renewed interest in this topic in light of an increased understanding of the genetic, molecular and systems-level events that underlie these complex processes [30-34].

Recent discoveries have shown a high level of integration between cellular signalling cascades [such as the cyclic AMP (cAMP), mitogen activated protein kinase (MAPK), and cAMP-responsive element binding protein (CREB)] pathway, that regulate circadian rhythms and memory processing. Disruption of circadian rhythms has negative consequences on memory and cognitive performance in various tasks and several species [35].

\section{Functions of melatonin}

Melatonin, the hormone of darkness ( $N$-acetyl-5-methoxytryptamine, MTG), had been first identified as the hormone of the pineal gland secreted into the cerebrospinal fluid, and it regulates patterns of sleeping and awakening in humans [36,37].

Over the past decade, melatonin's impact on chronobiological effects has been vastly scrutinized. Remarkably, melatonin affects the firing rate of the mammalian SCN and hippocampal CA1 neurons [38-41]. Therefore, circadian hormonal modulation of neuronal firing could be a general mechanism throughout the brain.

As a signalling molecule, melatonin is widely expressed throughout vertebrate and invertebrate human, zebrafish (Danio rerio), sea slugs (Apylsia californica), mice (Mus musculus), and flies (D. melanogaster) [42-46] and is secreted in a time-of-day-dependent manner [47]. Recently, melatonin synthesis has been suggested to interact with core circadian mechanisms [48].

Neurohormone MTG is an anti-inflammatory, antioxidant, and neuro-protectant agent. It plays numerous physiological roles as a modulator of the biological clock. Specifically, the sleep-wake cycle regulation of circadian rhythms, protection of mitochondria [49-55]. Furthermore, MTG is also believed to be involved in the modulation of learning and memory also enhance cognitive capacity [56-58], via its binding to receptors widely distributed throughout the brain [59-62].

Researchers also indicate that MTG may exert particular therapeutic effects in patients with Alzheimer's disease (AD) and Parkinson's disease [63-65] by protecting against neurotoxicity induced by amyloid-beta (A $\beta$ ) peptides [66-68]. Interestingly, some studies have shown that MTG attenuates pyramidal neuronal cell damage in the hippocampus in global cerebral ischemia [69-75].

\section{Melatonin and memory formation}

As the levels of melatonin and CREB expression gradually decrease with age in the hippocampus and prefrontal cortex [76-80]. Both are considered with the age-dependent memory formation or memory preservations or cognitive deficits mechanism [81].

To date, melatonin administration shows memory enhancement effects in multiple memory and age-related or impaired animal models [74,82-85].

The activation of CREB via phosphorylation in the hippocampus is an important signalling mechanism for enhancing memory processing. CREB is a well-studied transcription factor that mediates intracellular signalling events that regulate the circadian rhythms of memory [86], long-term memory [87], and a variety of downstream effectors in the hippocampus and enhance hippocampal memory processing [88].

Melatonin has been shown to phosphorylate CREB in animal models $[89,90]$. That may enhance memory, but the signalling mechanism between melatonin and CREB is hitherto unestablished.

Melatonin receptors have been identified (in vivo consideration) in the hippocampus of various animals [82-94], and activated via specific receptors in the hippocampus cells. Melatonin has been 


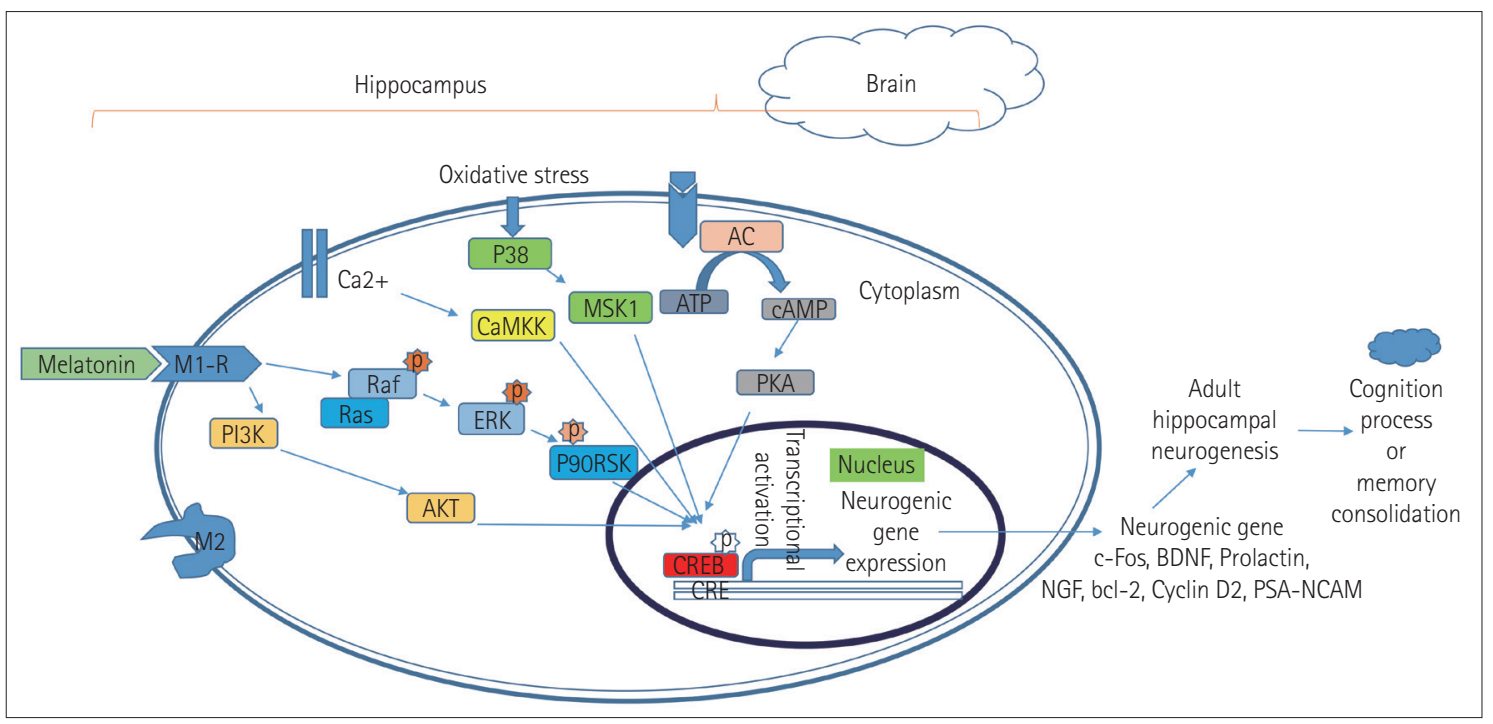

Figure 1. Specific melatonin receptor-mediated memory formation.

identified as a protector of pyramidal cells in the hippocampus and have long-term potentiation from damage in the case of non-receptor mediated actions [41]. Overall, the protective action of melatonin may be receptor-independent via free radical generating mechanisms [80] related to learning and memory [50].

To justify the inner mechanism, the in vitro assessment in HT22 cell line infers that melatonin treatment increases the level of Raf, ERK, p90RSK, CREB, and BDNF expression by consequence of phosphorylation. The expressed genes are associated with longterm memory formation and consolidations and referred that melatonin is associated with a variety of signaling mechanisms including the ERK and MAPK pathways (Figure 1) [82,95].

In recent times, a group of scientists from Tokyo Medical and Dental University found that melatonin and its metabolites [N1acetyl-N2-formyl-5-methoxykynuramine (AFMK) and N1-acetyl5-methoxykynuramine (AMK) in the brain] promote the formation of long-term memories in mice and protect against cognitive decline [96].

\section{Melatonin in the glymphatic system and cognitive functioning}

It has been reported that melatonin is attenuated during the ageing process and the patients with $\mathrm{AD}$ had a substantial reduction of this hormone. However, melatonin supplementation was found to minimize $A \beta$ neurotoxicity and formation while enhancing cognitive efficiency [97-103].

Early treatments with melatonin may be one of the most effective methods for developing approaches to postpone or avoid $A \beta$ and memory problems at this stage of the disease [103]. Melatonin crosses the blood-brain barrier in direct contrast to traditional antioxidants, is relatively free of toxicity, and is a possible therapeutic candidate in $\mathrm{AD}$ care, possibly due to enhancing the quality of sleep and clearance of $A \beta 42$ plaque by increasing the efficiency of the glymphatic system. Specifically, by promoting the glymphatic system function, deep sleep is essential in this clearance phase [104-108].

By the continuous interchange of fluids, the glymphatic system is a well-established waste clearance pathway of the brain. A primary driver of glymphatic clearance is sleep [109-112]. Nevertheless, research has started to appear on a wealth of other lifestyle choices such as sleep quality, amount, physical activity, body posture improvements, omega-3, chronic stress, intermittent fasting, and low alcohol doses. Glymphatic activity is gradually decreased with $\mathrm{AD}$ and ageing due to the loss of the water channels, $\mathrm{AQP} 4$ which facilitates fluid flow, with impaired interstitial solute clearance and increased aggregation [113,114].

Interestingly, a significant number of $\mathrm{AD}$ patients report increasing sleep disturbances along with the severity of the disease. $\mathrm{AD}$ and sleep disturbances signify a bidirectional relationship found before AD's clinical onset, where sleep disturbances occur with the frequency of $A \beta$, but often cause soluble $A \beta$ to increase. Overall, the findings support the hypothesis that it may reduce $\mathrm{AD}$ development due to melatonin's ability to promote sleep and act as an antioxidant [115-117]. It, therefore, increases cognitive function and decreases neuropathology in the model of mice, likely through glymphatic system activation (Figure 2) [118-122].

\section{SLEEP AND COGNITION}

\section{Sleep cycle}

Sleep is a multidimensional biochemical process to maintain homeostasis. It is categorized as a decline in consciousness and body responses to external stimuli, along with some brain electroencephalogram changes $[123,124]$. Complex shifts in the pattern of neuronal firing and neurotransmitter release [125] are followed by the transitions from wake up to sleep and between sleep phases. Rapid eye movement sleep (REM) and non-rapid eye movement sleep (n-REM), which alternate throughout the night in a roughly 90-minute cycle. n-REM sleep is further divided into three stages (Figure 3) [126]. 


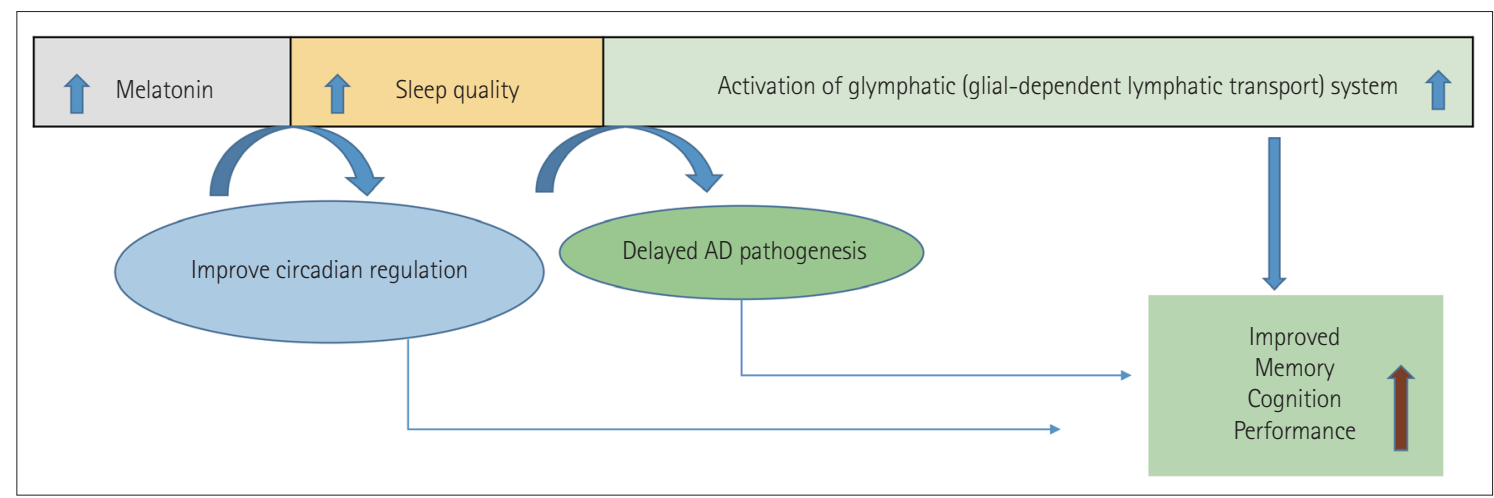

Figure 2. Melatonin and glial-dependent lymphatic enhance the cognitive process. AD: Alzheimer's disease.

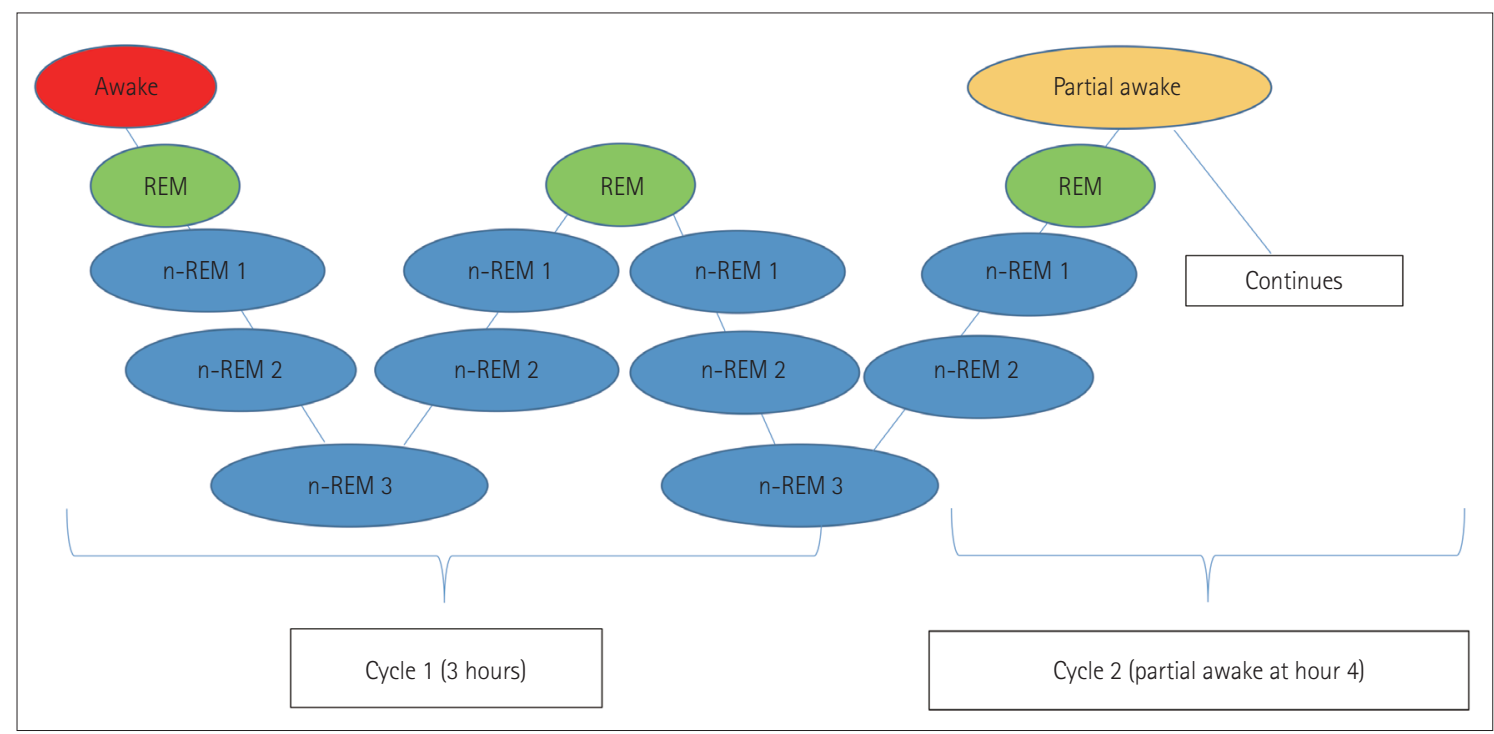

Figure 3. Schematic presentation of normal sleep structure where a complete cycle of rapid eye movement (REM) sleep and non-REM ( $\mathrm{n}-\mathrm{REM}$ ) sleep takes 3 hours to complete.

Neurobiology and biochemistry of sleep and wakefulness

To understand the relationship between sleep and cognition, it is required to find the particular region of the brain, which is involved in the sleeping and waking process. Richter's studies on the lesion inferred that a "master" clock is located in the hypothalamus [127]. Loss of behavioural and endocrine rhythms resulted in ablation of the SCN. Sleep homeostasis prevails at bedtime and SCN output is decreased, thus promoting sleep, while SCN output increases with little to no sleep pressure in the morning, thus promoting alertness [128-132].

Three primary factors affect the normal sleep and wake cycle: intrinsic circadian rhythm, behaviour of homeostatic inner sleep, and external factors [132-134]. Melatonin and light exposure are the core regulators of circadian rhythms. A few hours before bedtime, the melatonin level upsurges and assists sleep, and light exposure decreases melatonin secretion and disrupts sleep or improves wake-up.

Gamma-aminobutyric acid, galanin, and adenosine are the sleep-promoting neurotransmitters. While orexin (hypocretin), glutamate, norepinephrine, dopamine, serotonin, histamine, acetylcholine, and histamine are the key neurotransmitters that pro- mote wakefulness. Wakefulness is a moment when a neurophysiological perspective is formed. Through activation of reticular brain stem formation, secretion of norepinephrine, serotonin, and acetylcholine by the pons; and release of histamine by the posterior hypothalamus. In the lateral and posterior hypothalamus and its peptides and hormones, orexin/hypocretin neurons play a vital role in controlling eating, reward-seeking, reacting to arousal and metabolic signals to change vigilance states, addiction and stress; and in stabilizing both wakefulness and sleep (Figure 4) [135-143].

Production of n-REM sleep is coordinated by the ventrolateral preoptic nucleus in the anterior hypothalamus. During n-REM sleep, norepinephrine, serotonin, acetylcholine, and histamine release are decreased. The initiation of REM sleep is coordinated by communication between aminergic neurons, which produce norepinephrine, serotonin and histamine, and cholinergic neurons. During REM sleep, the aminergic neurons become nearly silent, while cholinergic neurons become highly active. These profound changes in a neurophysiological state seen across the sleep cycle, with the change of both in the activity of neuronal networks and the neurochemical milieu of the brain, suggest that sleep evolved 


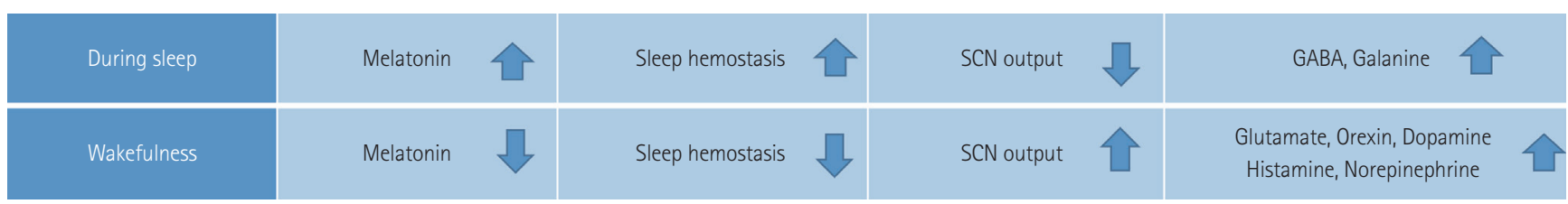

Figure 4. Differences between the changes in biochemical and physiological factors of sleep and wakefulness. SCN: suprachiasmatic nuclei.

as a period of altered cognitive processing $[144,145]$.

\section{Models of memory processing in sleep}

A significant correlation between sleep and cognitive processing has been well established over the past few years. In consolidating various forms of memory, sleep plays an important role and leads to reflective and inferential thought. Although the mechanism by which types of memories are stored in sleep remains unclear, numerous conceptual models have been presented.

The association of sleep and cognition primarily correlates three distinct dimensions: 1) the effects of sleep deprivation on cognition, 2) the influence of sleep on declarative and non-declarative memory consolidation, and 3) some proposed models of how sleep facilitates memory consolidation in sleep.

Wilson and colleagues $[146,147]$ conducted a neuronal level experiment on brain function in rats, which unveiled underlying query regarding the processes that occur in the brain during sleep and enables memory. They proposed the principle of "replay" of brain activity, as well as the re-appearance in sleep of brain activity that occurred during prior wakefulness and learning. They observed that during a spatial behavioural task, hippocampal cells that fired together during subsequent slow-wave sleep tended to replicate sequences of neuronal firing that indicate motion along a spatial path.

By measuring cerebral blood flow with positron emission tomography, Peigneux et al. [148] investigated regional brain activity in humans. They discovered that when subjects learned a route in a virtual town, hippocampal areas that were activated in humans showed increased activation during subsequent slow-wave sleep. Furthermore, the hippocampal activity also seen during slow-wave sleep was associated with the next day's task results. A similar effect, in a serial response time task, was also confirmed by Maquet et al. [149].

In subjects who had recently completed the task, several regions of the brain that were active during the execution of the task were significantly more active during REM sleep than in those who had not trained on the task. These outcomes can help researchers to conclude that during sleep, recently encoded memories are reactivated and "replayed".

The theory of synaptic homeostasis, which suggests that a process of synaptic downscaling occurs during sleep, particularly slow-wave sleep, is contrary to the notion that replaying during sleep improves memories [150,151].

As a means of conserving energy and space within the brain, total synaptic strength in the cortex is drastically reduced during this process. Such downscaling could indirectly gain learning and memory, according to some formulations of this model.

\section{TIMING OF FOOD AND SLEEP ON COGNITION}

Many aspects of cognition, including excitement, concentration, and working memory, are known to be affected by the timing of sleep. In rodents, sleep deprivation has been reported to decrease contextual fear memory in the first $5 \mathrm{~h}$ after training, despite otherwise sufficient sleep, but does not affect tone-cued fear memories $[152,153]$.

Spontaneous object recognition studies have shown that both object-recognition and object-location memories are impaired by 5-6 $\mathrm{h}$ of sleep deprivation after training [154-157], with an apparently crucial window at 3-4 $\mathrm{h}[158]$. Another test, which relies on undesired water immersion to enable animals to find a secret medium for observing the process of spatial learning and is responsive to hippocampal injury, is also essential for other brain regions and strategies [159].

Sleep architecture is also essential for memory, in addition to sleep duration. Humans sleep once a day in a consolidated bout and advance throughout the night over several periods of REM and NREM sleep. Daytime activity is compromised if this is fragmented and increased sleepiness occurs [160]. This phenomenon is also observed in a study conducted by Gupta et al. [161]. When comparing the $4 \mathrm{~h}$ drive to the $20 \mathrm{~h}$ drive, cognitive performance decreased during the night, with driving safety being questionable, including difficulty driving in the middle of the lane, adhering to the speed limit, and crashing.

Throughout the day and night, rodents sleep in numerous brief bursts consisting of both REM and n-REM sleep, with a sufficient amount of sleep during the light period, mainly due to increased sleep duration during the day [162].

Disturbing daily waking sleep architecture prevents the usual completion of sleep bouts, resulting in increased sleep pressure despite no improvement in the overall period of sleep [163]. Fragmentation of sleep also influences mechanisms of cognition. There are low learning and retention in the Morris water maze for mice subjected to sleep fragmentation for 15 days [164]. These studies indicate that disrupted sleep may lead to impaired performance in specific cognitive processes, even though sleep timing and overall sleep duration can remain comparable.

Data from mice experiment (missing GluA1) may provide some insight into the effects of these synaptic plasticity changes that 
take place during sleep. GluA1 deficient mice, such as the Morris water-maze, display unimpaired success on associative, long-term memory tasks. These species showed selective short-term deficits to recently experienced stimuli $[165,166]$.

These results indicate that the levels of synaptic GluA1 increase during waking, like an ongoing habit and a decrease in attention. This hypothesis suggests sleep can be necessary for restoring attentional efficiency [167].

There are multiple effects on cognition based on the time of food. Numerous studies have been conducted regarding this issue. Among these, in particular, eating a meal or not eating during the night shift to observe the success of attentive and careful driving. The performance of those who did not eat the meal during the night shift was better than the others [168].

Additionally, on the night shift, eating a big meal impairs cognitive efficiency and sleepiness beyond the consequences of nighttime alone. Shift workers can opt for a snack at night for enhanced efficiency [161].

In conclusion, while the cognitive function is unquestionably affected by the disruption of sleep and food timing, the specific cognitive processes affected and the underlying mechanisms involved are not straightforward. However, researchers should always be aware that due to a concomitant disruption of sleep and food timing, effects on cognition could arise.

\section{ROLE OF SHIFT WORK, ARTIFICIAL LIGHT, AND JET LAG}

There are multiple examples in our current world where lifestyle clashes with our internal biological clocks, including shift work and jet lag. Besides, artificial light results in light emission from electronic devices such as phones, tablets, and computers at inappropriate times of day, like a light at night, as well as exposure to light. As a result, there is rising concern about the effects on human health of circadian disturbance and aberrant light exposure, including impacts on metabolism, cardiovascular function, mental health, and even cancer risk [169-171].

A good number of studies have examined the impact of aberrant light exposure on cognitive performance. Rodents are used under the irregular light and dark (LD) cycles to investigate the underlying mechanisms of circadian disruption and correlation of adverse health conditions. During the usual subjective night, some result in light exposure; while others result in a mismatch between internal circadian time and external ambient time requiring a constant change of phase. It has been proposed that the negative effects of circadian disruption could be the reason for this mismatch [169].

To simulate the sudden change in time zones created by jet lag, shifting the LD period under which animals are housed has been used. A single advance or pause in the LD period is usually involved in acute jet lag protocols. Besides, persistent jet lag, which includes frequent $\mathrm{LD}$ cycle changes, has also been used as a circadian disturbance model [172].
Approximately $15 \%$ to $18 \%$ of all workers in Europe and the United States work on night shift schedules [173], and 15-30\% in Korea [174]. Night shift work has become a common occupation. It was calculated that the exposure levels of artificial light at night (ALAN) to shift staff at night ranged from $50 \mathrm{~lx}$ to $100 \mathrm{~lx}$, often reaching $200 \mathrm{~lx}$ [175]. At night, exposure to ALAN leads to melatonin suppression, clock gene expression changes, and sleep misalignment [174]. Acute suppression of melatonin after 1 hour of light exposure to the retina light inhibits sensitivity to melatonin by approximately $5 \%$ at $30 \mathrm{~lx}, 15 \%$ at $100 \mathrm{~lx}, 35 \%$ at $300 \mathrm{~lx}$, and $55 \%$ at $1000 \mathrm{~lx}$. After exposure to over $10000 \mathrm{~lx}$, maximal suppression was $70 \%[176,177]$.

When tested at waking time, night shift nurses reported significantly lower levels of the melatonin metabolite urinary 6-sulfatoxymelatonin (aMT6s) than day shift nurses. Night shift workers, however, did not exhibit peak levels of melatonin while sleeping during the day [178]. During the night, the peak melatonin levels occurred among nurses working rotating shifts, and when the nurses encountered ALAN levels below $80 \mathrm{~lx}$, melatonin levels were not different between night and day shift nurses [179]. In night shift workers, a decrease in melatonin suppression was observed, from $40.6 \%$ to $22.9 \%$, as the number of recent night shifts increased, indicating a phase shift or adaptation to night work [180].

Together, these findings show that using both acute and chronic jet lag protocols, ALAN, and night shift result in subtle changes in cognitive processes. However, given the effect of these protocols on both sleep fragmentation and arousal, the mechanisms by which cognitive processes are influenced are difficult to establish.

\section{CONCLUSION}

For a long time, melatonin was thought to be one of the possible inhibitors of long-term memory formation. However, after extensive research, it has been established as a neuroprotective hormone that regulates oversleeping, disease progression, circadian rhythms, and cognitive processes.

At a glance, initiation of quality sleep, clock gene regulation, circadian rhythm optimization, glymphatic system induction, and melatonin are considered a multidirectional compound to ensure body hemostasis and memory consolidation.

\section{Acknowledgments}

None

Conflicts of Interest

The authors have no potential conflicts of interest to disclose.

\section{Author Contributions}

Conceptualization: Md. Arifur Rahman Chowdhury, Md Mazedul Haq, Chandresh Sharma. Data curation: Md. Arifur Rahman Chowdhury, Md Mazedul Haq. Formal analysis: Md. Arifur Rahman Chowdhury, Md Mazedul Haq. Methodology: Md. Arifur Rahman Chowdhury, Md Mazedul Haq, Chandresh 
Sharma. Project administration: Md. Arifur Rahman Chowdhury, Md Mazedul Haq, Chandresh Sharma. Resources: Md. Arifur Rahman Chowdhury, Md Mazedul Haq, Chandresh Sharma. Software: Md. Arifur Rahman Chowdhury, Md Mazedul Haq, Chandresh Sharma. Supervision: Chandresh Sharma. Validation: Chandresh Sharma. Visualization: Narayan Kumar, Chandresh Sharma. Writing_original draft: Md. Arifur Rahman Chowdhury, Md Mazedul Haq, Chandresh Sharma. Writingreview \& editing: all authors.

\section{ORCID iDs}

Md. Arifur Rahman Chowdhury

https://orcid.org/0000-0003-1874-3147

Md Mazedul Haq ()

https://orcid.org/0000-0002-3912-3695

Narayan Kumar (10

https://orcid.org/0000-0002-4121-1053

Chandresh Sharma (1)

https://orcid.org/0000-0002-2813-302X

\section{REFERENCES}

1. Kaufmann CN, Eyler LT. The role of sleep in accelerated cognitive aging in bipolar disorder. Chronobiol Med 2019;1:66-68.

2. Turek FW. Circadian clocks: not your grandfather's clock. Science 2016; 354:992-993.

3. Bernard S, Gonze D, Cajavec B, Herzel H, Kramer A. Synchronization-induced rhythmicity of circadian oscillators in the suprachiasmatic nucleus. PLoS Comput Biol 2007;3:e68.

4. Figueiro MG. Disruption of circadian rhythms by light during day and night. Curr Sleep Med Rep 2017;3:76-84.

5. Reppert SM, Weaver DR. Coordination of circadian timing in mammals. Nature 2002;418:935-941.

6. Meijer JH, Michel S. Neurophysiological analysis of the suprachiasmatic nucleus: a challenge at multiple levels. Methods Enzymol 2015;552:75-102.

7. Moore RY, Eichler VB. Loss of a circadian adrenal corticosterone rhythm following suprachiasmatic lesions in the rat. Brain Res 1972;42:201-206.

8. Richter CP. Inborn nature of the rat's 24 -hour clock. J Comp Physiol Psychol 1971;75:1-4.

9. Stephan FK, Zucker I. Circadian rhythms in drinking behavior and locomotor activity of rats are eliminated by hypothalamic lesions. Proc Natl Acad Sci U S A 1972;69:1583-1586.

10. Turek FW. Circadian neural rhythms in mammals. Annu Rev Physiol 1985; 47:49-64.

11. Ralph MR, Foster RG, Davis FC, Menaker M. Transplanted suprachiasmatic nucleus determines circadian period. Science 1990;247:975-978.

12. Welsh DK, Logothetis DE, Meister M, Reppert SM. Individual neurons dissociated from rat suprachiasmatic nucleus express independently phased circadian firing rhythms. Neuron 1995;14:697-706.

13. Cermakian N, Sassone-Corsi P. Multilevel regulation of the circadian clock. Nat Rev Mol Cell Biol 2000;1:59-67.

14. King DP, Takahashi JS. Molecular genetics of circadian rhythms in mammals. Annu Rev Neurosci 2000;23:713-742.

15. Shearman LP, Zylka MJ, Weaver DR, Kolakowski LF Jr, Reppert SM. Two period homologs: circadian expression and photic regulation in the suprachiasmatic nuclei. Neuron 1997;19:1261-1269.

16. Hogenesch JB, Gu YZ, Jain S, Bradfield CA. The basic-helix-loop-helix-PAS orphan MOP3 forms transcriptionally active complexes with circadian and hypoxia factors. Proc Natl Acad Sci U S A 1998;95:5474-5479.

17. Bunger MK, Wilsbacher LD, Moran SM, Clendenin C, Radcliffe LA, Hogenesch JB, et al. Mop3 is an essential component of the master circadian pacemaker in mammals. Cell 2000;103:1009-1017.

18. Balsalobre A, Damiola F, Schibler U. A serum shock induces circadian gene expression in mammalian tissue culture cells. Cell 1998;93:929-937.

19. Konopka RJ, Benzer S. Clock mutants of Drosophila melanogaster. Proc Natl Acad Sci U S A 1971;68:2112-2116.

20. Bargiello TA, Jackson FR, Young MW. Restoration of circadian behavioural rhythms by gene transfer in Drosophila. Nature 1984;312:752-754.

21. Reddy P, Zehring WA, Wheeler DA, Pirrotta V, Hadfield C, Hall JC, et al. Molecular analysis of the period locus in Drosophila melanogaster and identification of a transcript involved in biological rhythms. Cell 1984; 38:701-710.

22. Panda S, Hogenesch JB, Kay SA. Circadian rhythms from flies to human. Nature 2002;417:329-335.

23. Gallego M, Virshup DM. Post-translational modifications regulate the ticking of the circadian clock. Nat Rev Mol Cell Biol 2007;8:139-148.

24. Lyons LC, Green CL, Eskin A. Intermediate-term memory is modulated by the circadian clock. J Biol Rhythms 2008;23:538-542.

25. Sakai T, Tamura T, Kitamoto T, Kidokoro Y. A clock gene, period, plays a key role in long-term memory formation in Drosophila. Proc Natl Acad Sci U S A 2004;101:16058-16063.

26. Jeong J, Lee Y, Cho CH, Lee HJ. Circadian gene variations are associated with obsessive-compulsive behaviors in a young healthy Korean population. Chronobiol Med 2019;1:115-120.

27. Folkard S, Wever RA, Wildgruber CM. Multi-oscillatory control of circadian rhythms in human performance. Nature 1983;305:223-226.

28. Monk TH, Weitzman ED, Fookson JE, Moline ML, Kronauer RE, Gander PH. Task variables determine which biological clock controls circadian rhythms in human performance. Nature 1983;304:543-545.

29. Monk TH, Weitzman ED, Fookson JE, Moline ML. Circadian rhythms in human performance efficiency under free-running conditions. Chronobiologia 1984;11:343-354.

30. Davies JA, Navaratnam V, Redfern PH. A 24-hour rhythm in passive-avoidance behaviour in rats. Psychopharmacologia 1973;32:211-214.

31. Holloway FA, Wansley RA. Multiple retention deficits at periodic intervals after active and passive avoidance learning. Behav Biol 1973;9:1-14.

32. Tapp WN, Holloway FA. Phase shifting circadian rhythms produces retrograde amnesia. Science 1981;211:1056-1058.

33. Fekete M, van Ree JM, Niesink RJ, de Wied D. Disrupting circadian rhythms in rats induces retrograde amnesia. Physiol Behav 1985;34:883-887.

34. Gerstner JR, Lyons LC, Wright KP, Loh DH, Rawashdeh O, Eckel-Mahan KL, et al. Cycling behavior and memory formation. J Neurosci 2009;29: 12824-12830.

35. Takahashi JS, Hong HK, Ko CH, McDearmon EL. The genetics of mammalian circadian order and disorder: implications for physiology and disease. Nat Rev Genet 2008;9:764-775.

36. Fu W, Xie H, Laudon M, Zhou S, Tian S, You Y. Piromelatine ameliorates memory deficits associated with chronic mild stress-induced anhedonia in rats. Psychopharmacology (Berl) 2016;233:2229-2239.

37. Sharif R, Aghsami M, Gharghabi M, Sanati M, Khorshidahmad T, Vakilzadeh G, et al. Melatonin reverses H-89 induced spatial memory deficit: involvement of oxidative stress and mitochondrial function. Behav Brain Res 2017;316:115-124.

38. McArthur AJ, Gillette MU, Prosser RA. Melatonin directly resets the rat suprachiasmatic circadian clock in vitro. Brain Res 1991;565:158-161.

39. Rusak B, Yu GD. Regulation of melatonin-sensitivity and firing-rate rhythms of hamster suprachiasmatic nucleus neurons: pinealectomy effects. Brain Res 1993;602:200-204.

40. Starkey SJ, Walker MP, Beresford IJ, Hagan RM. Modulation of the rat suprachiasmatic circadian clock by melatonin in vitro. Neuroreport 1995;6: 1947-1951.

41. Musshoff U, Riewenherm D, Berger E, Fauteck JD, Speckmann EJ. Melatonin receptors in rat hippocampus: molecular and functional investigations. Hippocampus 2002;12:165-173.

42. Benloucif S, Guico MJ, Reid KJ, Wolfe LF, L'hermite-Balériaux M, Zee PC. Stability of melatonin and temperature as circadian phase markers and their relation to sleep times in humans. J Biol Rhythms 2005;20:178-188.

43. Cahill GM. Circadian regulation of melatonin production in cultured zebrafish pineal and retina. Brain Res 1996;708:177-181.

44. Abran D, Anctil M, Ali MA. Melatonin activity rhythms in eyes and cerebral ganglia of Aplysia californica. Gen Comp Endocrinol 1994;96:215-222.

45. Goto M, Oshima I, Tomita T, Ebihara S. Melatonin content of the pineal 
gland in different mouse strains. J Pineal Res 1989;7:195-204.

46. Hintermann E, Grieder NC, Amherd R, Brodbeck D, Meyer UA. Cloning of an arylalkylamine N-acetyltransferase (aaNAT1) from Drosophila melanogaster expressed in the nervous system and the gut. Proc Natl Acad Sci U S A 1996;93:12315-12320.

47. Pandi-Perumal SR, Srinivasan V, Maestroni GJ, Cardinali DP, Poeggeler B, Hardeland R. Melatonin: nature's most versatile biological signal? FEBS J 2006;273:2813-2838.

48. Shimomura K, Lowrey PL, Vitaterna MH, Buhr ED, Kumar V, Hanna P, et al. Genetic suppression of the circadian Clock mutation by the melatonin biosynthesis pathway. Proc Natl Acad Sci U S A 2010;107:8399-8403.

49. Hardeland R, Cardinali DP, Brown GM, Pandi-Perumal SR. Melatonin and brain inflammaging. Prog Neurobiol 2015;127-128:46-63.

50. Manchester LC, Coto-Montes A, Boga JA, Andersen LP, Zhou Z, Galano A, et al. Melatonin: an ancient molecule that makes oxygen metabolically tolerable. J Pineal Res 2015;59:403-419.

51. Moretti R, Zanin A, Pansiot J, Spiri D, Manganozzi L, Kratzer I, et al. Melatonin reduces excitotoxic blood-brain barrier breakdown in neonatal rats. Neuroscience 2015;311:382-397.

52. Rudnitskaya EA, Muraleva NA, Maksimova KY, Kiseleva E, Kolosova NG, Stefanova NA. Melatonin attenuates memory impairment, amyloid- $\beta$ accumulation, and neurodegeneration in a rat model of sporadic Alzheimer's disease. J Alzheimers Dis 2015;47:103-116.

53. Zhang S, Wang P, Ren L, Hu C, Bi J. Protective effect of melatonin on soluble A $\beta 1$-42-induced memory impairment, astrogliosis, and synaptic dysfunction via the Musashi1/Notch1/Hes1 signaling pathway in the rat hippocampus. Alzheimers Res Ther 2016;8:40.

54. Huang F, Yang Z, Liu X, Li CQ. Melatonin facilitates extinction, but not acquisition or expression, of conditional cued fear in rats. BMC Neurosci 2014; 15:86.

55. Rawashdeh O, Maronde E. The hormonal Zeitgeber melatonin: role as a circadian modulator in memory processing. Front Mol Neurosci 2012; 5:27.

56. Morgan PJ, Barrett P, Howell HE, Helliwell R. Melatonin receptors: localization, molecular pharmacology and physiological significance. Neurochem Int 1994;24:101-146.

57. Bertaina-Anglade V, Drieu-La-Rochelle C, Mocaër E, Seguin L. Memory facilitating effects of agomelatine in the novel object recognition memory paradigm in the rat. Pharmacol Biochem Behav 2011;98:511-517.

58. He P, Ouyang X, Zhou S, Yin W, Tang C, Laudon M, et al. A novel melatonin agonist Neu-P11 facilitates memory performance and improves cognitive impairment in a rat model of Alzheimer' disease. Horm Behav 2013;64: $1-7$.

59. Argyriou A, Prast H, Philippu A. Melatonin facilitates short-term memory. Eur J Pharmacol 1998;349:159-162.

60. Barceló P, Nicolau C, Gamundí A, Fiol MA, Tresguerres JA, Akaârir M, et al. Comparing the behavioural effects of exogenous growth hormone and melatonin in young and old Wistar rats. Oxid Med Cell Longev 2016;2016: 5863402.

61. Pandi-Perumal SR, BaHammam AS, Brown GM, Spence DW, Bharti VK, Kaur C, et al. Melatonin antioxidative defense: therapeutical implications for aging and neurodegenerative processes. Neurotox Res 2013;23:267-300.

62. Furio AM, Brusco LI, Cardinali DP. Possible therapeutic value of melatonin in mild cognitive impairment: a retrospective study. J Pineal Res 2007; 43:404-409.

63. Esteban S, Nicolaus C, Garmundi A, Rial RV, Rodríguez AB, Ortega E, et al. Effect of orally administered L-tryptophan on serotonin, melatonin, and the innate immune response in the rat. Mol Cell Biochem 2004;267:39-46.

64. Rosales-Corral SA, Acuña-Castroviejo D, Coto-Montes A, Boga JA, Manchester LC, Fuentes-Broto L, et al. Alzheimer's disease: pathological mechanisms and the beneficial role of melatonin. J Pineal Res 2012;52:167-202.

65. Khan ZA, Hong Y, Choi J, Lee Y, Jin Y, Hong Y. Melatonin: a potent therapeutic candidate in degenerative neural damages. Chronobiol Med 2020; 2:85-95.

66. Mukda S, Panmanee J, Boontem P, Govitrapong P. Melatonin administration reverses the alteration of amyloid precursor protein-cleaving secretases expression in aged mouse hippocampus. Neurosci Lett 2016;621:3946.

67. Rudnitskaya EA, Maksimova KY, Muraleva NA, Logvinov SV, Yanshole
LV, Kolosova NG, et al. Beneficial effects of melatonin in a rat model of sporadic Alzheimer's disease. Biogerontology 2015;16:303-316.

68. Cardinali DP, Vigo DE, Olivar N, Vidal MF, Furio AM, Brusco LI. Therapeutic application of melatonin in mild cognitive impairment. Am J Neurodegener Dis 2012;1:280-291.

69. Lee CH, Park JH, Ahn JH, Won MH. Effects of melatonin on cognitive impairment and hippocampal neuronal damage in a rat model of chronic cerebral hypoperfusion. Exp Ther Med 2016;11:2240-2246.

70. Lee CH, Yoo KY, Choi JH, Park OK, Hwang IK, Kwon YG, et al. Melatonin's protective action against ischemic neuronal damage is associated with up-regulation of the MT2 melatonin receptor. J Neurosci Res 2010; 88:2630-2640.

71. Lee EJ, Lee MY, Chen HY, Hsu YS, Wu TS, Chen ST, et al. Melatonin attenuates gray and white matter damage in a mouse model of transient focal cerebral ischemia. J Pineal Res 2005;38:42-52.

72. Letechipía-Vallejo G, López-Loeza E, Espinoza-González V, GonzálezBurgos I, Olvera-Cortés ME, Moralí G, et al. Long-term morphological and functional evaluation of the neuroprotective effects of post-ischemic treatment with melatonin in rats. J Pineal Res 2007;42:138-146.

73. Lee MY, Kuan YH, Chen HY, Chen TY, Chen ST, Huang CC, et al. Intravenous administration of melatonin reduces the intracerebral cellular inflammatory response following transient focal cerebral ischemia in rats. J Pineal Res 2007;42:297-309.

74. Tyagi E, Agrawal R, Nath C, Shukla R. Effect of melatonin on neuroinflammation and acetylcholinesterase activity induced by LPS in rat brain. Eur J Pharmacol 2010;640:206-210.

75. Lee B, Shim I, Lee H, Hahm DH. Melatonin ameliorates cognitive memory by regulation of cAMP-response element-binding protein expression and the anti-inflammatory response in a rat model of post-traumatic stress disorder. BMC Neurosci 2018;19:38.

76. Kudo K, Wati H, Qiao C, Arita J, Kanba S. Age-related disturbance of memory and CREB phosphorylation in CA1 area of hippocampus of rats. Brain Res 2005;1054:30-37.

77. Hardeland R. Melatonin and the theories of aging: a critical appraisal of melatonin's role in antiaging mechanisms. J Pineal Res 2013;55:325-356.

78. Schmid HA. Decreased melatonin biosynthesis, calcium flux, pineal gland calcification and aging: a hypothetical framework. Gerontology 1993;39: 189-199.

79. Reiter RJ. The pineal gland and melatonin in relation to aging: a summary of the theories and of the data. Exp Gerontol 1995;30:199-212.

80. Zhang HM, Zhang Y. Melatonin: a well-documented antioxidant with conditional pro-oxidant actions. J Pineal Res 2014;57:131-146.

81. Bekinschtein P, Cammarota M, Igaz LM, Bevilaqua LR, Izquierdo I, Medina JH. Persistence of long-term memory storage requires a late protein synthesis- and BDNF- dependent phase in the hippocampus. Neuron 2007; 53:261-277.

82. Cui P, Yu M, Luo Z, Dai M, Han J, Xiu R, et al. Intracellular signaling pathways involved in cell growth inhibition of human umbilical vein endothelial cells by melatonin. J Pineal Res 2008;44:107-114.

83. Reiter RJ. The ageing pineal gland and its physiological consequences. Bioessays 1992;14:169-175.

84. Corrales A, Martínez P, García S, Vidal V, García E, Flórez J, et al. Longterm oral administration of melatonin improves spatial learning and memory and protects against cholinergic degeneration in middle-aged Ts65Dn mice, a model of Down syndrome. J Pineal Res 2013;54:346-358.

85. Cheng S, Ma C, Qu H, Fan W, Pang J, He H. Differential effects of melatonin on hippocampal neurodegeneration in different aged accelerated senescence prone mouse-8. Neuro Endocrinol Lett 2008;29:91-99.

86. Yoo DY, Kim W, Lee CH, Shin BN, Nam SM, Choi JH, et al. Melatonin improves D-galactose-induced aging effects on behavior, neurogenesis, and lipid peroxidation in the mouse dentate gyrus via increasing pCREB expression. J Pineal Res 2012;52:21-28.

87. Ali T, Badshah H, Kim TH, Kim MO. Melatonin attenuates D-galactoseinduced memory impairment, neuroinflammation and neurodegeneration via RAGE/NF-K B/JNK signaling pathway in aging mouse model. J Pineal Res 2015;58:71-85.

88. Flood JF, Morley JE. Learning and memory in the SAMP8 mouse. Neurosci Biobehav Rev 1998;22:1-20.

89. O’Neal-Moffitt G, Pilli J, Kumar SS, Olcese J. Genetic deletion of MT1/MT2 
melatonin receptors enhances murine cognitive and motor performance. Neuroscience 2014;277:506-521.

90. Liu Y, Ni C, Li Z, Yang N, Zhou Y, Rong X, et al. Prophylactic melatonin attenuates isoflurane-induced cognitive impairment in aged rats through hippocampal melatonin receptor 2 - cAMP response element binding signalling. Basic Clin Pharmacol Toxicol 2017;120:219-226.

91. Nonno R, Lucini V, Pannacci M, Mazzucchelli C, Angeloni D, Fraschini F, et al. Pharmacological characterization of the human melatonin Mella receptor following stable transfection into NIH3T3 cells. Br J Pharmacol 1998;124:485-492.

92. Mazzucchelli C, Pannacci M, Nonno R, Lucini V, Fraschini F, Stankov BM. The melatonin receptor in the human brain: cloning experiments and distribution studies. Brain Res Mol Brain Res 1996;39:117-126.

93. Wan Q, Man HY, Liu F, Braunton J, Niznik HB, Pang SF, et al. Differential modulation of GABAA receptor function by Mella and Mellb receptors. Nat Neurosci 1999;2:401-403.

94. Srinivasan V, Pandi-Perumal SR, Maestroni GJ, Esquifino AI, Hardeland R, Cardinali DP. Role of melatonin in neurodegenerative diseases. Neurotox Res 2005;7:293-318.

95. Liu J, Clough SJ, Hutchinson AJ, Adamah-Biassi EB, Popovska-Gorevski M, Dubocovich ML. MT1 and MT2 melatonin receptors: a therapeutic perspective. Annu Rev Pharmacol Toxicol 2016;56:361-383.

96. Iwashita H, Matsumoto Y, Maruyama Y, Watanabe K, Chiba A, Hattori A. The melatonin metabolite N1-acetyl-5-methoxykynuramine facilitates long-term object memory in young and aging mice. J Pineal Res 2021;70: e12703.

97. Jessen NA, Munk AS, Lundgaard I, Nedergaard M. The glymphatic system: a beginner's guide. Neurochem Res 2015;40:2583-2599.

98. Plog BA, Nedergaard M. The glymphatic system in central nervous system health and disease: past, present, and future. Annu Rev Pathol 2018;13:379394.

99. Spinedi E, Cardinali DP. Neuroendocrine-metabolic dysfunction and sleep disturbances in neurodegenerative disorders: focus on Alzheimer's disease and melatonin. Neuroendocrinology 2019;108:354-364.

100. Pagano ES, Spinedi E, Gagliardino JJ. White adipose tissue and circadian rhythm dysfunctions in obesity: pathogenesis and available therapies. Neuroendocrinology 2017;104:347-363.

101. Pappolla MA, Matsubara E, Vidal R, Pacheco-Quinto J, Poeggeler B, Zagorski $\mathrm{M}$, et al. Melatonin treatment enhances $\mathrm{A} \beta$ lymphatic clearance in a transgenic mouse model of amyloidosis. Curr Alzheimer Res 2018;15: 637-642.

102. Zlokovic BV. The blood-brain barrier in health and chronic neurodegenerative disorders. Neuron 2008;57:178-201.

103. Tai LM, Mehra S, Shete V, Estus S, Rebeck GW, Bu G, et al. Soluble apoE/ $\mathrm{A} \beta$ complex: mechanism and therapeutic target for APOE4-induced $\mathrm{AD}$ risk. Mol Neurodegener 2014;9:2.

104. Arbon EL, Knurowska M, Dijk DJ. Randomised clinical trial of the effects of prolonged-release melatonin, temazepam and zolpidem on slow-wave activity during sleep in healthy people. J Psychopharmacol 2015;29:764776.

105. Buckner RL, Snyder AZ, Shannon BJ, LaRossa G, Sachs R, Fotenos AF, et al. Molecular, structural, and functional characterization of Alzheimer's disease: evidence for a relationship between default activity, amyloid, and memory. J Neurosci 2005;25:7709-7717.

106. Gorfine T, Assaf Y, Goshen-Gottstein Y, Yeshurun Y, Zisapel N. Sleep-anticipating effects of melatonin in the human brain. Neuroimage 2006;31: 410-418.

107. Haimov I, Laudon M, Zisapel N, Souroujon M, Nof D, Shlitner A, et al. Sleep disorders and melatonin rhythms in elderly people. BMJ 1994;309: 167.

108. Hita-Yañez E, Atienza M, Gil-Neciga E, Cantero JL. Disturbed sleep patterns in elders with mild cognitive impairment: the role of memory decline and ApoE $\varepsilon 4$ genotype. Curr Alzheimer Res 2012;9:290-297.

109. Landry GJ, Liu-Ambrose T. Buying time: a rationale for examining the use of circadian rhythm and sleep interventions to delay progression of mild cognitive impairment to Alzheimer's disease. Front Aging Neurosci 2014; 6:325.

110. Lemoine $P$, Zisapel N. Prolonged-release formulation of melatonin (Circadin) for the treatment of insomnia. Expert Opin Pharmacother 2012;13:
895-905.

111. Saper CB, Scammell TE, Lu J. Hypothalamic regulation of sleep and circadian rhythms. Nature 2005;437:1257-1263.

112. Al-Aama T, Brymer C, Gutmanis I, Woolmore-Goodwin SM, Esbaugh J, Dasgupta M. Melatonin decreases delirium in elderly patients: a randomized, placebo-controlled trial. Int J Geriatr Psychiatry 2011;26:687-694.

113. Hatta K, Kishi Y, Wada K, Takeuchi T, Odawara T, Usui C, et al. Preventive effects of ramelteon on delirium: a randomized placebo-controlled trial. JAMA Psychiatry 2014;71:397-403.

114. de Jonghe A, van Munster BC, Goslings JC, Kloen P, van Rees C, Wolvius $\mathrm{R}$, et al. Effect of melatonin on incidence of delirium among patients with hip fracture: a multicentre, double-blind randomized controlled trial. CMAJ 2014;186:E547-E556.

115. Poeggeler B, Miravalle L, Zagorski MG, Wisniewski T, Chyan YJ, Zhang Y, et al. Melatonin reverses the profibrillogenic activity of apolipoprotein E4 on the Alzheimer amyloid Abeta peptide. Biochemistry 2001;40:1499515001 .

116. Trotti LM, Karroum EG. Melatonin for sleep disorders in patients with neurodegenerative diseases. Curr Neurol Neurosci Rep 2016;16:63.

117. McCleery J, Cohen DA, Sharpley AL. Pharmacotherapies for sleep disturbances in Alzheimer's disease. Cochrane Database Syst Rev 2014;(3) CD009178.

118. Lucey BP, Bateman RJ. Amyloid- $\beta$ diurnal pattern: possible role of sleep in Alzheimer's disease pathogenesis. Neurobiol Aging 2014;35 Suppl 2:S29S34.

119. Musiek ES, Xiong DD, Holtzman DM. Sleep, circadian rhythms, and the pathogenesis of Alzheimer disease. Exp Mol Med 2015;47:e148.

120. Ray CA. Melatonin attenuates the sympathetic nerve responses to orthostatic stress in humans. J Physiol 2003;551(Pt 3):1043-1048.

121. Riemersma-van der Lek RF, Swaab DF, Twisk J, Hol EM, Hoogendijk WJ, Van Someren EJ. Effect of bright light and melatonin on cognitive and noncognitive function in elderly residents of group care facilities: a randomized controlled trial. JAMA 2008;299:2642-2655.

122. Tan DX, Hardeland R, Manchester LC, Poeggeler B, Lopez-Burillo S, Mayo JC, et al. Mechanistic and comparative studies of melatonin and classic antioxidants in terms of their interactions with the ABTS cation radical. J Pineal Res 2003;34:249-259.

123. Purves D, Augustine GJ, Fitzpatrick D, Katz LC, LaMantiaAS, McNamara JO, et al. Neuroscience. 2nd ed. Sunderland, MA: Sinauer Associates; 2001.

124. Chokroverty S. Overview of sleep \& sleep disorders. Indian J Med Res 2010; 131:126-140.

125. España RA, Scammell TE. Sleep neurobiology for the clinician. Sleep 2004; 27:811-820.

126. Yang JH, Choi SH, Lee MH, Oh SM, Choi JW, Park JE, et al. Automated assessment of quantitative REM sleep without atonia for diagnosis of REM sleep behavior disorder. Chronobiol Med 2020;2:123-128.

127. Richter CP. Biological clocks in medicine and psychiatry: shock-phase hypothsis. Proc Natl Acad Sci U S A 1960;46:1506-1530.

128. Hendrickson AE, Wagoner N, Cowan WM. An autoradiographic and electron microscopic study of retino-hypothalamic connections. Z Zellforsch Mikrosk Anat 1972;135:1-26.

129. Moore RY, Lenn NJ. A retinohypothalamic projection in the rat. J Comp Neurol 1972;146:1-14.

130. Moore RY. Retinohypothalamic projection in mammals: a comparative study. Brain Res 1973;49:403-409.

131. Avidan A, Barkoukis T. Review of sleep medicine. Philadelphia: Butterworth-Heinemann; 2007.

132. Kryger M, Roth T, Dement T. Principles and practice of sleep medicine. 4th ed. Philadelphia: Saunders; 2005.

133. Koukkou M. Functional states of the brain: their determinants. Amsterdam: Elsevier Science; 1980.

134. Achermann P, Borbély AA. Mathematical models of sleep regulation. Front Biosci 2003;8:s683-s693.

135. Watson CJ, Baghdoyan HA, Lydic R. Neuropharmacology of sleep and wakefulness. Sleep Med Clin 2010;5:513-528.

136. Inutsuka A, Yamanaka A. The physiological role of orexin/hypocretin neurons in the regulation of sleep/wakefulness and neuroendocrine functions. Front Endocrinol (Lausanne) 2013;4:18.

137. Winsky-Sommerer R, Yamanaka A, Diano S, Borok E, Roberts AJ, Sakurai 
$\mathrm{T}$, et al. Interaction between the corticotropin-releasing factor system and hypocretins (orexins): a novel circuit mediating stress response. J Neurosci 2004;24:11439-11448.

138. Hara J, Gerashchenko D, Wisor JP, Sakurai T, Xie X, Kilduff TS. Thyrotropin-releasing hormone increases behavioral arousal through modulation of hypocretin/orexin neurons. J Neurosci 2009;29:3705-3714.

139. Xie X, Crowder TL, Yamanaka A, Morairty SR, Lewinter RD, Sakurai T, et al. GABA(B) receptor-mediated modulation of hypocretin/orexin neurones in mouse hypothalamus. J Physiol 2006;574(Pt 2):399-414.

140. Li Y, Gao XB, Sakurai T, van den Pol AN. Hypocretin/orexin excites hypocretin neurons via a local glutamate neuron-a potential mechanism for orchestrating the hypothalamic arousal system. Neuron 2002;36:1169-1181.

141. Yamanaka A, Muraki Y, Tsujino N, Goto K, Sakurai T. Regulation of orexin neurons by the monoaminergic and cholinergic systems. Biochem Biophys Res Commun 2003;303:120-129.

142. Yamanaka A, Muraki Y, Ichiki K, Tsujino N, Kilduff TS, Goto K, et al. Orexin neurons are directly and indirectly regulated by catecholamines in a complex manner. J Neurophysiol 2006;96:284-298.

143. Kumar S, Szymusiak R, Bashir T, Rai S, McGinty D, Alam MN. Effects of serotonin on perifornical-lateral hypothalamic area neurons in rat. Eur $J$ Neurosci 2007;25:201-212.

144. Deak MC, Stickgold R. Sleep and cognition. Wiley Interdiscip Rev Cogn Sci 2010;1:491-500.

145. Elbaz I, Levitas-Djerbi T, Appelbaum L. The hypocretin/orexin neuronal networks in zebrafish. Curr Top Behav Neurosci 2017;33:75-92.

146. Wilson MA, McNaughton BL. Reactivation of hippocampal ensemble memories during sleep. Science 1994;265:676-679.

147. Lee AK, Wilson MA. Memory of sequential experience in the hippocampus during slow wave sleep. Neuron 2002;36:1183-1194.

148. Peigneux P, Laureys S, Fuchs S, Collette F, Perrin F, Reggers J, et al. Are spatial memories strengthened in the human hippocampus during slow wave sleep? Neuron 2004;44:535-545.

149. Maquet P, Laureys S, Peigneux P, Fuchs S, Petiau C, Phillips C, et al. Experience-dependent changes in cerebral activation during human REM sleep. Nat Neurosci 2000;3:831-836.

150. Tononi G, Cirelli C. Sleep function and synaptic homeostasis. Sleep Med Rev 2006;10:49-62.

151. Kong N, Choi J, Seo WS. Evaluation of sleep problems or disorders using sleep questionnaires. Chronobiol Med 2019;1:144-148.

152. Basner M, Rao H, Goel N, Dinges DF. Sleep deprivation and neurobehavioral dynamics. Curr Opin Neurobiol 2013;23:854-863.

153. Graves LA, Heller EA, Pack AI, Abel T. Sleep deprivation selectively impairs memory consolidation for contextual fear conditioning. Learn Mem 2003;10:168-176

154. Florian C, Vecsey CG, Halassa MM, Haydon PG, Abel T. Astrocyte-derived adenosine and $\mathrm{A} 1$ receptor activity contribute to sleep loss-induced deficits in hippocampal synaptic plasticity and memory in mice. J Neurosci 2011;31:6956-6962.

155. Halassa MM, Florian C, Fellin T, Munoz JR, Lee SY, Abel T, et al. Astrocytic modulation of sleep homeostasis and cognitive consequences of sleep loss. Neuron 2009;61:213-219.

156. Havekes R, Bruinenberg VM, Tudor JC, Ferri SL, Baumann A, Meerlo P, et al. Transiently increasing cAMP levels selectively in hippocampal excitatory neurons during sleep deprivation prevents memory deficits caused by sleep loss. J Neurosci 2014;34:15715-15721.

157. Palchykova S, Winsky-Sommerer R, Meerlo P, Dürr R, Tobler I. Sleep deprivation impairs object recognition in mice. Neurobiol Learn Mem 2006; 85:263-271.

158. Prince TM, Wimmer M, Choi J, Havekes R, Aton S, Abel T. Sleep deprivation during a specific 3-hour time window post-training impairs hippocampal synaptic plasticity and memory. Neurobiol Learn Mem 2014;109: 122-130.

159. Garthe A, Kempermann G. An old test for new neurons: refining the Mor- ris water maze to study the functional relevance of adult hippocampal neurogenesis. Front Neurosci 2013;7:63.

160. Stepanski EJ. The effect of sleep fragmentation on daytime function. Sleep 2002;25:268-276

161. Gupta CC, Centofanti S, Dorrian J, Coates A, Stepien JM, Kennaway D, et al. Altering meal timing to improve cognitive performance during simulated nightshifts. Chronobiol Int 2019;36:1691-1713.

162. Mitler MM, Lund R, Sokolove PG, Pittendrigh CS, Dement WC. Sleep and activity rhythms in mice: a description of circadian patterns and unexpected disruptions in sleep. Brain Res 1977;131:129-145.

163. Baud MO, Magistretti PJ, Petit JM. Sustained sleep fragmentation induces sleep homeostasis in mice. Sleep 2015;38:567-579.

164. Ramesh V, Nair D, Zhang SX, Hakim F, Kaushal N, Kayali F, et al. Disrupted sleep without sleep curtailment induces sleepiness and cognitive dysfunction via the tumor necrosis factor- $\alpha$ pathway. J Neuroinflammation 2012;9:91.

165. Sanderson DJ, Bannerman DM. Competitive short-term and long-term memory processes in spatial habituation. J Exp Psychol Anim Behav Process 2011;37:189-199.

166. Sanderson DJ, Good MA, Skelton K, Sprengel R, Seeburg PH, Rawlins JN, et al. Enhanced long-term and impaired short-term spatial memory in GluA1 AMPA receptor subunit knockout mice: evidence for a dual-process memory model. Learn Mem 2009;16:379-386.

167. Vyazovskiy VV, Walton ME, Peirson SN, Bannerman DM. Sleep homeostasis, habits and habituation. Curr Opin Neurobiol 2017;44:202-211.

168. Gupta CC, Dorrian J, Grant CL, Pajcin M, Coates AM, Kennaway DJ, et al. It's not just what you eat but when: the impact of eating a meal during simulated shift work on driving performance. Chronobiol Int 2017;34:66-77.

169. Foster RG, Wulff K. The rhythm of rest and excess. Nat Rev Neurosci 2005; 6:407-414.

170. West AC, Bechtold DA. The cost of circadian desynchrony: evidence, insights and open questions. Bioessays 2015;37:777-788.

171. Wulff K, Gatti S, Wettstein JG, Foster RG. Sleep and circadian rhythm disruption in psychiatric and neurodegenerative disease. Nat Rev Neurosci 2010;11:589-599.

172. Cho $\mathrm{CH}$, Lee Y. The chronobiologic-based practical approach to shift work. Chronobiol Med 2019;1:103-106.

173. Straif K, Baan R, Grosse Y, Secretan B, El Ghissassi F, Bouvard V, et al. Carcinogenicity of shift-work, painting, and fire-fighting. Lancet Oncol 2007;8: $1065-1066$

174. Park TJ, Paek DM, Joh KO, Park JS, Cho SI. The relationship between shift work and work-related injuries among Korean workers. Korean J Occup Environ Med 2012;24:52-60.

175. Hunter CM, Figueiro MG. Measuring light at night and melatonin levels in shift workers: a review of the literature. Biol Res Nurs 2017;19:365-374.

176. Lunn RM, Blask DE, Coogan AN, Figueiro MG, Gorman MR, Hall JE, et al. Health consequences of electric lighting practices in the modern world: a report on the National Toxicology Program's workshop on shift work at night, artificial light at night, and circadian disruption. Sci Total Environ 2017;607-608:1073-1084

177. Grundy A, Sanchez M, Richardson H, Tranmer J, Borugian M, Graham CH, et al. Light intensity exposure, sleep duration, physical activity, and biomarkers of melatonin among rotating shift nurses. Chronobiol Int 2009; 26:1443-1461.

178. Choukroun J, Geoffroy PA. Light therapy in mood disorders: a brief history with physiological insights. Chronobiol Med 2019;1:3-8.

179. Grundy A, Tranmer J, Richardson H, Graham CH, Aronson KJ. The influence of light at night exposure on melatonin levels among Canadian rotating shift nurses. Cancer Epidemiol Biomarkers Prev 2011;20:2404-2412.

180. Papantoniou K, Pozo OJ, Espinosa A, Marcos J, Castaño-Vinyals G, Basagaña $X$, et al. Circadian variation of melatonin, light exposure, and diurnal preference in day and night shift workers of both sexes. Cancer Epidemiol Biomarkers Prev 2014;23:1176-1186. 